\title{
Identifying and quantitating defects on chemical vapor de- position grown graphene layers by selected electrochemical deposition of Au nanoparticles
}

\author{
Hye-Mi So ${ }^{1}$, Jeong Hun Mun², Gyeong Sook Bang ${ }^{1}$, Taek Yong Kim², Byung Jin Cho ${ }^{2, \star}$ and Chi Won Ahn ${ }^{1, \star}$ \\ ${ }^{1}$ National Nanofab Center, Daejeon 305-806, Korea \\ ${ }^{2}$ Department of Electrical Engineering, Korea Advanced Institute of Science and Technology, Daejeon 305-701, Korea
}

\author{
Article Info \\ Received 5 September 2011 \\ Accepted 10 December 2011 \\ *Corresponding Author \\ E-mail: cwahn@nnfc.re.kr \\ bjcho@ee.kaist.ac.kr \\ Tel: $+82-42-879-9725$ \\ $+82-42-350-3485$

\section{Open Access} \\ DOI: http://dx.doi.org/ \\ 10.5714/CL.2012.13.1.056 \\ This is an Open Access article distributed \\ under the terms of the Creative Commons \\ Attribution Non-Commercial License \\ (http://creativecommons.org/licenses/ \\ by-nc/3.0/) which permits unrestricted \\ non-commercial use, distribution, and \\ reproduction in any medium, provided \\ the original work is properly cited.
}

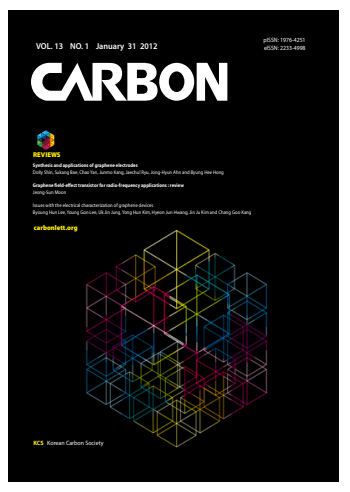

http://carbonlett.org

pISSN: $1976-4251$

eISSN: 2233-4998

Copyright $\odot$ Korean Carbon Society

\begin{abstract}
The defect sites on chemical vapor deposition grown graphene are investigated through the selective electrochemical deposition (SED) of Au nanoparticles. For SED of Au nanoparticles, an engineered potential pulse is applied to the working electrode versus the reference electrode, thereby highlighting the defect sites, which are more reactive relative to the pristine surface. Most defect sites decorated by $\mathrm{Au}$ nanoparticles are situated along the $\mathrm{Cu}$ grain boundaries, implying that the origin of the defects lies in the synthesis of uneven graphene layers on the rough $\mathrm{Cu}$ surface.
\end{abstract}

Key words: graphene, Au nanoparticle, defect decoration

\section{Introduction}

Since mono-layer graphene was isolated by Geim and Novoselov, numerous studies focused on various applications of graphene have been carried out in efforts to realize graphene-based devices. In this regard, the synthesis of large-area, high-quality graphene is a fundamental requirement. To date, epitaxial growth on $\mathrm{SiC}$ [1-3], chemical vapor deposition (CVD) methods on catalytic metal substrates [4-9], and chemical reduction of graphite oxide [10-13] have been widely studied for large-scale graphene synthesis. Notably, Hong and his colleagues [14] recently showed that the CVD method enables the synthesis of 30 -inch wide high quality graphene. However, due to imperfect crystallinity and inherent defects, these synthetic graphene films have lower carrier mobility than mechanically cleaved graphene. For the measuring of the inherent defects in CVD grown graphene layers, Raman spectroscopy, atomic force microscopy (AFM), scanning electron microscopy (SEM), and tunneling electron microscopy are typically utilized. However, these methods are not suitable for the quantitative analysis of defects in graphene over a large area. Selective electrochemical deposition (SED), on the other hand, is a possible solution for efficient and quantitative measurement of the defect densities in synthetic graphene layers. Because the defect sites of graphene are more reactive than the pristine $\mathrm{sp}^{2}$ bonded graphene lattice, defect sites can be decorated with high selectivity [15-21].

Here, we carried out SED of Au nanoparticles on defect sites on CVD grown graphene layers, and the origin of the defects is suggested on the basis of the results.

\section{Experimental}

\subsection{Graphene synthesis and sample preparation}

The graphene layer was synthesized on the $\mathrm{Cu}$ surface by the CVD process using radio- 

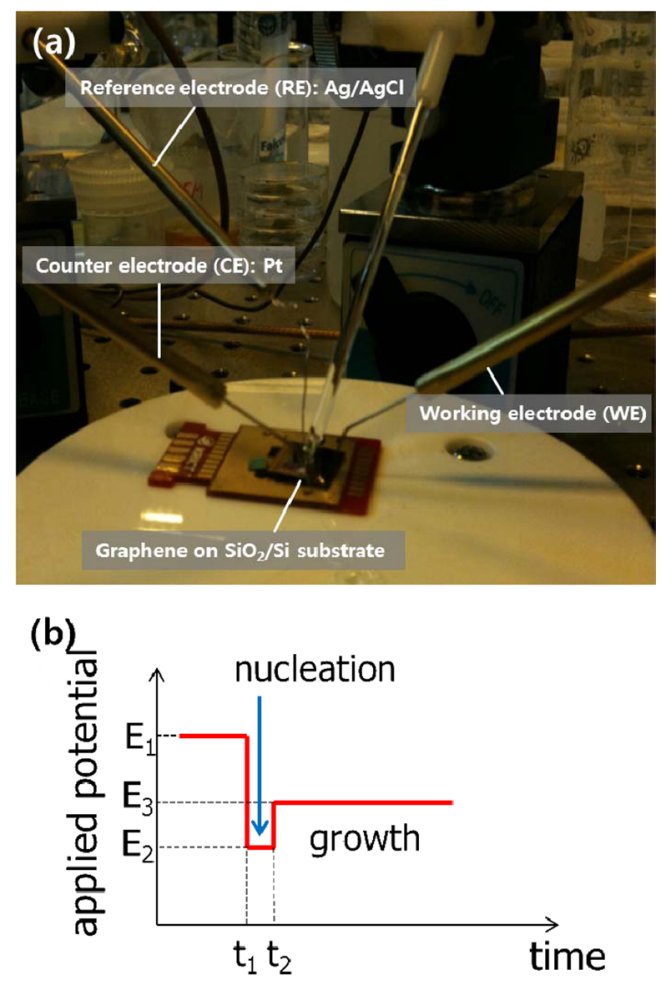

Fig. 1. (a) Measurement configuration for selective electrochemical deposition of Au nanoparticles. (b) The engineered potential pulse to enhance the selectivity of Au nanoparticle deposition.

frequency (RF) plasma. A $300 \mathrm{~nm}$ thick $\mathrm{Cu}$ film deposited on top of a $\mathrm{Si}$ wafer with a $300 \mathrm{~nm}$ thick $\mathrm{SiO}_{2}$ layer was inserted in an inductively coupled plasma CVD system. After ramping up temperature to $725^{\circ} \mathrm{C}$ under $\mathrm{Ar}$ ambient at 50 mtorr, the sample was treated by $\mathrm{H}_{2}$ plasma with a gas flow rate of $40 \mathrm{sccm}$ and $\mathrm{RF}$ plasma power of $50 \mathrm{~W}$ for $2 \mathrm{~min}$. A gas mixture of Ar and $\mathrm{C}_{2} \mathrm{H}_{2}\left(\mathrm{Ar}: \mathrm{C}_{2} \mathrm{H}_{2}=40: 1 \mathrm{sccm}\right)$ was then flowed into the chamber with $150 \mathrm{~W}$ RF plasma for the graphene synthesis. The graphene layer synthesized on the $\mathrm{Cu}$ surface was finally transferred onto the $\mathrm{SiO}_{2}(300 \mathrm{~nm}) / \mathrm{Si}$ using a poly(methyl methacrylate) supporting layer and wet etching of the metal film.

\subsection{Au decoration}

To selectively decorate Au nanoparticles on graphene, we used electrochemical deposition. Employing a multi-potential system, we controlled both the nanoparticle size and packing density. A droplet of $\mathrm{HAuCl}_{4}$ in $100 \mathrm{mM} \mathrm{KCl}$ (supporting electrolyte) was placed on the device and transferred graphene was used as a working electrode. A reduction potential was then applied with respect to an $\mathrm{Ag}|\mathrm{AgCl}| \mathrm{KCl}$ (3M) reference electrode with current monitoring using a Pt counter-electrode.

\subsection{SEM and energy dispersive $X$-ray spec- troscopy analysis}

The Au particle decorated graphene samples were observed by a field-emission SEM/energy dispersive X-ray spectroscopy
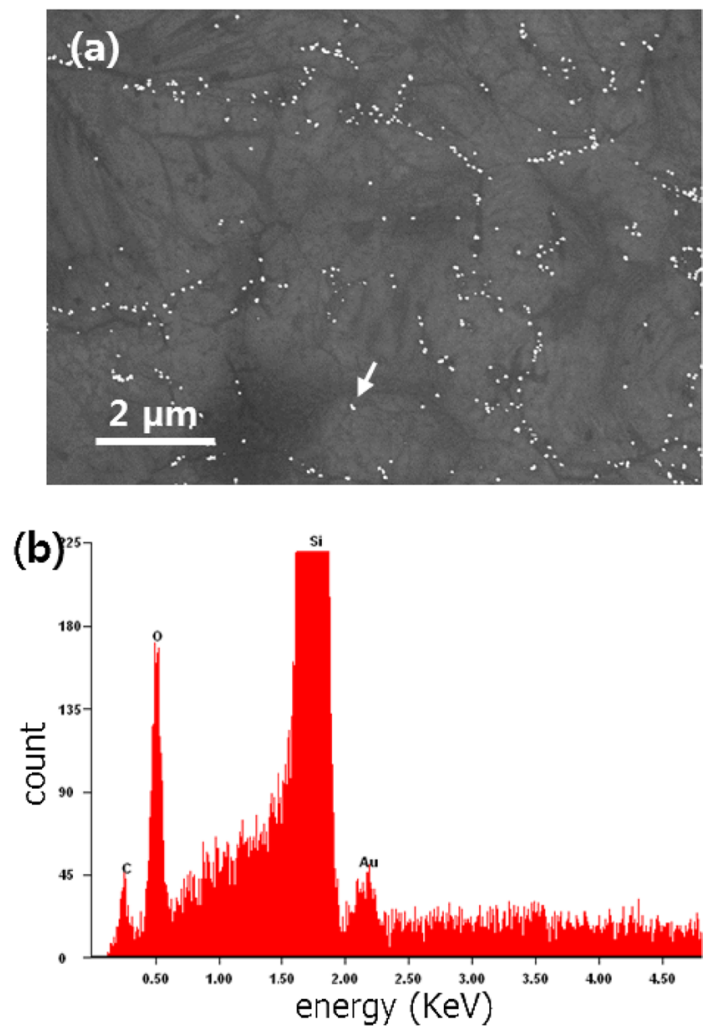

(c)

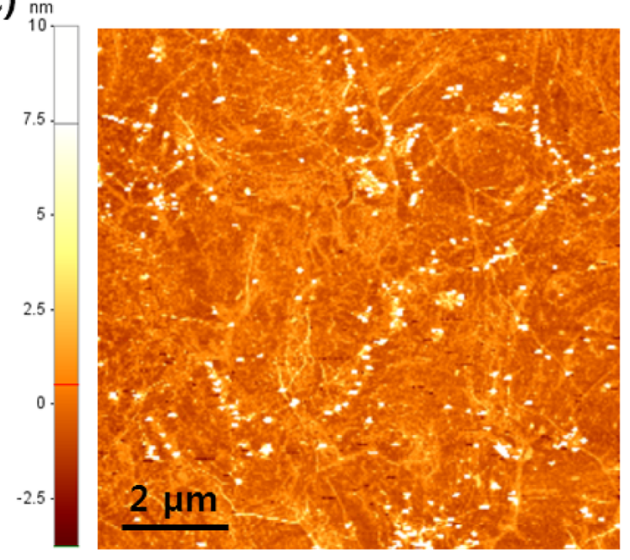

Fig. 2. (a) Scanning electron microscopy image, (b) energy dispersive X-ray spectroscopy spectrum, and (c) atomic force microscopy image of graphene surface on $\mathrm{SiO} / \mathrm{Si}$ substrate after selective electrochemical deposition of Au nanoparticles.

(EDAX) system (FEI Sirion SEM with an EDAX, The Netherlands). Prior to observation, the samples were placed on a metal stub with double sided carbon adhesive tape. The scanning energy for the EDAX analysis ranged from 0 to $4.75 \mathrm{KeV}$.

\section{Results and Discussion}

The measurement configuration and engineered potential pulse are shown in Fig. 1. A drop of $50 \mu \mathrm{M} \mathrm{HAuCl}_{4}$ solution was placed onto the transferred graphene. Deposition of Au nanopar- 

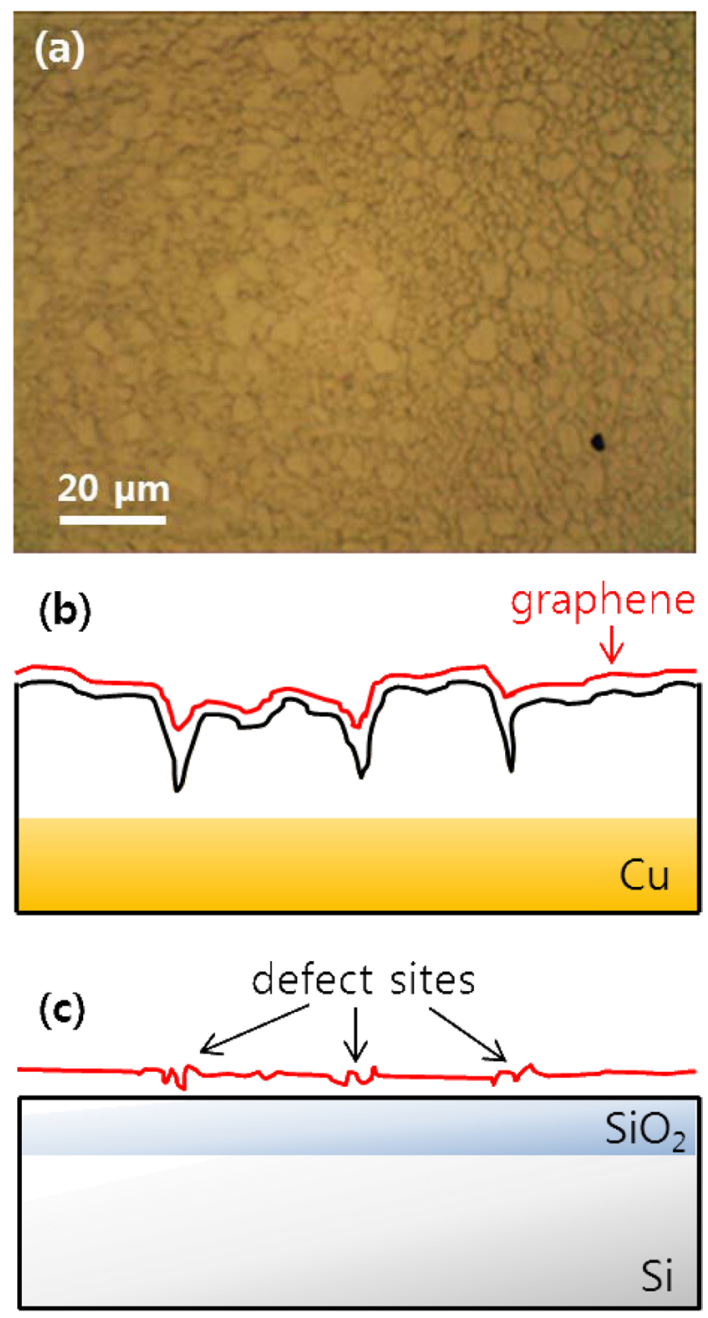

Fig. 3. (a) Microscope image of Cu surface after graphene synthesis, showing a highly agglomerated and roughened surface. Cross-sectional view of the sample (b) after graphene formation on the Cu substrate and (c) after layer transfer onto the flat $\mathrm{SiO}_{2} / \mathrm{Si}$ substrate.

ticles entailed three steps: protection, nucleation, and growth. The first step for the protected Au particles was applied at $1 \mathrm{~V}$ for $3 \mathrm{~s}$. Following the first step, a pulse with $\mathrm{E}_{2}=-0.6 \mathrm{~V}$ for 50 $\mathrm{ms}$ initiates nucleation at the prepared sites. Growth was continued at $\mathrm{E}_{3}=0.6 \mathrm{~V}$ for $1 \mathrm{~s}$. We typically obtained roughly $30-\mathrm{nm}$ size Au nanoparticles using the above method. An SEM image of the Au nanoparticle decorated graphene surface is presented in Fig. 2a. As reported earlier, wrinkles caused by different coefficients of thermal expansion between graphene and the $\mathrm{Cu}$ substrate and mechanical stress induced during layer transfer are observed over the entire graphene surface $[8,9]$. The shape and density of these wrinkles are more clearly shown in the AFM image (Fig. 2c). After SED by an engineered potential pulse, $\mathrm{Au}$ nanoparticles are situated in specific positions, as shown in Figs. $2 \mathrm{a}$ and $\mathrm{c}$. The EDAX spectrum for a white particle (white arrow) in the SEM image (Fig. 2b) exhibits a clear Au peak, implying the nucleation and growth of Au nanoparticles. Even though there are numerous wrinkles over the whole graphene surface, as shown in the SEM and AFM images, most Au nanoparticles are not located on these defects but instead form a specific shape that resembles a grain boundary of the $\mathrm{Cu}$ substrate shown in Fig. 3a. The $\mathrm{Cu}$ surface is inevitably agglomerated and roughened during the graphene synthesis because of the high temperature annealing, an essential process for high quality synthesis of high quality graphene layers. Thus, as shown in Fig. 3b, the graphene layers are synthesized along the highly roughened $\mathrm{Cu}$ surface. During the layer transfer of synthetic graphene onto the flat $\mathrm{SiO}_{2} / \mathrm{Si}$ substrate, this uneven graphene layer is folded, and defect sites are formed on the graphene layer (Fig. 3c). Consequently, the higher reaction energy of these defects caused by the rough surface of $\mathrm{Cu}$ attracts the $\mathrm{Au}$ nanoparticles.

\section{Conclusions}

In this work, we have quantitatively investigated the defects on large size, high quality graphene layers grown by the CVD method via SED of Au nanoparticles. By adjusting the potential applied to the graphene, selective deposition of Au nanoparticles on specific defect sites was achieved. Comparing the positions of defect sites and the $\mathrm{Cu}$ grain boundary, it is confirmed that most defect sites are caused by the unevenly synthesized graphene along the rough $\mathrm{Cu}$ surface.

\section{Acknowledgments}

This work was supported by the National Research Foundation of Korea (NRF) Research Grant, 2008-2002744, 20100029132, and 2011-0017333.

\section{References}

[1] Berger C, Song Z, Li X, Wu X, Brown N, Naud C, Mayou D, Li T, Hass J, Marchenkov AN, Conrad EH, First PN, De Heer WA. Electronic confinement and coherence in patterned epitaxial graphene. Science, 312, 1191 (2006). http://dx.doi.org/10.1126/science.1125925.

[2] Virojanadara C, Syväjarvi M, Yakimova R, Johansson LI, Zakharov AA, Balasubramanian T. Homogeneous large-area graphene layer growth on 6H-SiC(0001). Phys Rev B, 78, 245403 (2008). http://dx.doi.org/10.1103/PhysRevB.78.245403.

[3] Emtsev KV, Bostwick A, Horn K, Jobst J, Kellogg GL, Ley L, McChesney JL, Ohta T, Reshanov SA, Rohrl J, Rotenberg E, Schmid AK, Waldmann D, Weber HB, Seyller T. Towards wafer-size graphene layers by atmospheric pressure graphitization of silicon carbide. Nature Mater, 8, 203 (2009). http://dx.doi. org/10.1038/nmat2382.

[4] Obraztsov AN, Obraztsova EA, Tyurnina AV, Zolotukhin AA. Chemical vapor deposition of thin graphite films of nanometer thickness. Carbon, 45, 2017 (2007). http://dx.doi.org/10.1016/j. carbon.2007.05.028.

[5] Yu Q, Lian J, Siriponglert S, Li H, Chen YP, Pei SS. Graphene segregated on Ni surfaces and transferred to insulators. Appl Phys Lett, 93, 113103 (2008). http://dx.doi.org/10.1063/1.2982585.

[6] Reina A, Jia X, Ho J, Nezich D, Son H, Bulovic V, Dresselhaus MS, Jing K. Large area, few-layer graphene films on arbitrary 
substrates by chemical vapor deposition. Nano Lett, 9, 30 (2009). http://dx.doi.org/10.1021/n1801827v.

[7] Kim KS, Zhao Y, Jang H, Lee SY, Kim JM, Ahn JH, Kim P, Choi JY, Hong BH. Large-scale pattern growth of graphene films for stretchable transparent electrodes. Nature, 457, 706 (2009). http:// dx.doi.org/10.1038/nature07719.

[8] Kang BJ, Mun JH, Hwang CY, Cho BJ. Monolayer graphene growth on sputtered thin film platinum. J Appl Phys, 106, 104309 (2009). http://dx.doi.org/10.1063/1.3254193.

[9] Li X, Cai W, An J, Kim S, Nah J, Yang D, Piner R, Velamakanni A, Jung I, Tutuc E, Banerjee SK, Colombo L, Ruoff RS. Large-area synthesis of high-quality and uniform graphene films on copper foils. Science, 324, 1312 (2009). http://dx.doi.org/10.1126/science. 1171245

[10] Li X, Wang X, Zhang L, Lee S, Dai H. Chemically derived, ultrasmooth graphene nanoribbon semiconductors. Science, 319, 1229 (2008). http://dx.doi.org/10.1126/science.1150878.

[11] Li X, Zhang G, Bai X, Sun X, Wang X, Wang E, Dai H. Highly conducting graphene sheets and Langmuir-Blodgett films. Nature Nanotechnol, 3, 538 (2008). http://dx.doi.org/10.1038/nnano.2008.210.

[12] Eda G, Fanchini G, Chhowalla M. Large-area ultrathin films of reduced graphene oxide as a transparent and flexible electronic material. Nature Nanotechnol, 3, 270 (2008). http://dx.doi.org/10.1038/ nnano.2008.83.

[13] Li D, Muller MB, Gilje S, Kaner RB, Wallace GG. Processable aqueous dispersions of graphene nanosheets. Nature Nanotechnol, 3, 101 (2008). http://dx.doi.org/10.1038/nnano.2007.451.

[14] Bae S, Kim H, Lee Y, Xu X, Park JS, Zheng Y, Balakrishnan J,
Lei T, Ri Kim H, Song YI, Kim YJ, Kim KS, Ozyilmaz B, Ahn $\mathrm{JH}$, Hong BH, Iijima S. Roll-to-roll production of 30-inch graphene films for transparent electrodes. Nature Nanotechnol, 5, 574 (2010). http://dx.doi.org/10.1038/nnano.2010.132.

[15] Zach MP, Ng KH, Penner RM. Molybdenum nanowires by electrodeposition. Science, 290, 2120 (2000). http://dx.doi.org/10.1126/ science.290.5499.2120.

[16] Penner RM. Mesoscopic metal particles and wires by electrodeposition. J Phys Chem B, 106, 3339 (2002). http://dx.doi.org/10.1021/ jp013219o.

[17] Walter EC, Zach MP, Favier F, Murray BJ, Inazu K, Hemminger JC, Penner RM. Metal nanowire arrays by electrodeposition. Chem Phys Chem, 4, 131 (2003). http://dx.doi.org/10.1002/ cphc.200390022.

[18] Banks CE, Davies TJ, Wildgoose GG, Compton RG. Electrocatalysis at graphite and carbon nanotube modified electrodes: edgeplane sites and tube ends are the reactive sites. Chem Commun, 7, 829 (2005). http://dx.doi.org/10.1039/b413177k.

[19] Fan Y, Goldsmith BR, Collins PG. Identifying and counting point defects in carbon nanotubes. Nature Mater, 4, 906 (2005). http:// dx.doi.org/10.1038/nmat1516.

[20] Mubeen S, Zhang T, Chartuprayoon N, Rheem Y, Mulchandani A, Myung NV, Deshusses MA. Sensitive detection of H2S using gold nanoparticle decorated single-walled carbon nanotubes. Anal Chem, 82, 250 (2010). http://dx.doi.org/10.1021/ac901871d.

[21] Kim YT, Han JH, Hong BH, Kwon YU. Electrochemical Synthesis of CdSe quantum-Dot arrays on a graphene basal plane using mesoporous silica thin-film templates. Adv Mater, 22, 515 (2010). http://dx.doi.org/10.1002/adma.200902736. 